\title{
Progressive Focal Degenerative Disease of the Posterior Associative Cortex
}

\author{
Ezzedine Attig, Jean Jacquy, Patrick Uytdenhoef and Hervé Roland
}

\begin{abstract}
A 72-year-old man developed a very progressive neuropsychologic deficit 6 years ago, beginning with isolated visual topographic memory disturbances and visuo-constructive apraxia without additional manifestations of dementia. The syndrome worsened thereafter with the emergence of visual agnosia, simultagnosia, psychic paralysis of gaze, auditivo-verbal agnosia, and recently an amnestic syndrome with confabulation and confusion (at the end of 1989). CT scans, which remained unchanged over the years, showed mild, focal atrophic changes revealed by dilatation of the right occipital horn. His angiograms were normal. Two SPECT studies (with HMPAO measurements), performed 6 years from the onset, detected marked hypoperfusion in both parieto-occipital regions, mainly on the right side. Progressive focal degenerative disease without dementia is a relatively new syndrome, especially in cases with progressive aphasia. ${ }^{1}$ As noted in our patient, progressive disturbances initially localized in the right parieto-occipital region followed by posterior bilobar degeneration (pronounced on the right side) without dementia until late in the course may represent another exceptionally reported characteristic of this new syndrome. It is suggested that this variant of the Mesulam syndrome is more likely explained by progressive atrophy of the Alzheimer type.

RÉSUMÉ: Atteinte neurodégénérative focale des aires associatives du cortex postérieur. Un patient de 72 ans a développé 6 ans plus tôt un déficit neuropsychologique progressif débutant par une perturbation isolée de la mémoire topographique visuelle associée à une apraxie visuo-constructive mais sans autre manifestation cognitive suggérant une démence. Ce syndrome s'est aggravé très progressivement par l'apparition d'une agnosie visuelle, de simultagnosie, de paralysie psychique du regard, et d'agnosie auditivo-verbale. En 1989, soit après 6 ans d'évolution, il a développé un syndrome amnésique avec confabulation puis, quelques mois plus tard, un état confusionnel. Les CT scans cérébraux, demeurés inchangés au fil de l'évolution, montraient une atrophie modérée au niveau de la région pariéto-occipitale droite révélée par une dilatation ventriculaire de la corne occipitale. L'angiographie cérébrale était normale. Deux études débitmétriques (SPECT, HMPAO) réalisées en 1989 détectaient des hypoperfusions postérieures bilatérales pariétooccipitales, nettement plus marquées à droite. Ce type de syndrome, qui rentre dans le cadre d'une atteinte neurodégénérative focale sans signe de démence classique, sauf en phase tardive, est connu seulement depuis $1982^{1}$ dans des cas d'aphasie progressive. Dans notre cas, les symptômes initiaux du patient étaient attribués à un dysfonctionnement localisé au niveau de la région parioto-occipitale droite et il n'y eut évidence de démence que beaucoup plus tard. Ceci représente, par sa localisation, une autre caractéristique exceptionnellement décrite dans ce nouveau syndrome. Nous suggérons que cette variante postérieure du syndrome de Mesulam pourrait être expliquée par une atrophie focale dégénérative progressive du type Alzheimer.
\end{abstract}

Can. J. Neurol. Sci. 1993; 20: 154-157

Since Mesulam's original description ${ }^{1}$ in 1982 of 6 patients with primary progressive aphasia without generalized dementia, reports of this syndrome have been increasing. ${ }^{2-18}$ The syndrome probably results from a degenerative process which differs pathologically from classical conditions such as Alzheimer's disease (AD). ${ }^{2}$ This focal degenerative process in the CNS has also been reported in cases of progressive apraxia without dementia, ${ }^{19-22}$ and is detected in more posterior regions. ${ }^{21.23} \mathrm{We}$ describe another patient with this type of condition documented by SPECT studies.

\section{CASE REPORT}

A 72-year-old, right-handed man with no significant previous medical record except a minor cranial trauma in January 1983, no significant familial history and no ethylism presented with insidious and very progressive visual disturbances in 1984. He had difficulty finding his way in familiar areas (topographic memory deficit), manipulating objects in his lateral visual fields, and working simultaneously with 2 or more objects. His remaining higher brain functions, i.e., judgment, insight, and other kinds of memory, were preserved. There was no ideational or ideomotor apraxia, agnosia or aphasia. On examination (August 1986), he was alert, oriented, and in good physical condition. Basic neurologic

From the Department of Neurology (E.A., J.J., P.U., H.R.), Hôpital Civil de Charleroi, Charleroi, Belgium, affiliated with the Free University of Brussels; and the Department of Neurology (E.A.), Hôtel-Dieu Hospital, Montréal

Received July 23, 1992. Accepted in final form December 15, 1992

Presented at the second meeting of the European Neurological Society, Brighton, United Kingdom, June 30 - July 4, 1990

Reprint requests to: Dr. E. Attig, Dept. of Neurology, Hôtel-Dieu Hospital, 3840 Saint-Urbain, Montréal, PQ, Canada H2W IT8 
evaluation disclosed inconstant left visual extinction. Neuropsychologic assessment revealed an inability to realize complex tasks with several sequences, simultagnosia, optic ataxia, visuospatial defects (Rey's complex figure and labyrinthine tests), and visuo-constructional impairment (block design test). These disturbances were mainly attributed to posterior lesions in the right hemisphere (the left hemisphere could have been involved to a lesser degree). EEG showed very mild, diffuse dysrhythmia without paroxysmal or periodic activities. A CT scan divulged mild atrophic changes in the right occipital horn of the lateral ventricle. From 1986 to 1989 , we regularly noted worsening of his symptoms with the appearance of new neuropsychologic deficits. He became increasingly disoriented in finding his way, developed visual (for things, colors and prosopagnosia) and auditory (for atypical noises) agnosia, and had ideational and ideomotor apraxia. He denied the severity of his condition. Left tactile and visual extinctions became evident on neurologic examination, but his EEG remained unchanged. Digitized intravenous angiography was normal except for mild carotid atheromatosis. On reevaluation in June 1989, he acted as though he was blind with confabulation and loss of judgment which severely interfered with his daily activities. Meaningful neuropsychologic testing could not be performed because of the severe impairment present at this stage of the disease. His EEG and CT scans were unchanged. A SPECT study (Figure 1) showed marked hypoperfusion in parieto-occipital areas, especially on the right side. At the end of 1989, he was readmitted in an advanced state of deterioration with confabulation and confusion. EEG, CT scan, and SPECT were unchanged.

\section{Discussion and Conclusion}

For 5 to 6 years, our patient presented a gradual isolated deficit (topographic memory impairment and visuo-constructive apraxia), later becoming more compromised by ideational or ideomotor apraxia and visual and auditory agnosia but without disorientation, loss of judgment, dysphasia, or other neurologic abnormalities (except for variable left visual extinction). At 6 years after onset, he developed mild to severe signs of dementia. Progressive neuropsychologic symptoms without dementia or leading only to a late state of dementia are rare. Most of the reported cases with senile or presenile onset are of the aphasic type (progressive aphasia without dementia), described initially by Mesulam ${ }^{1,2}$ and later by others. ${ }^{3-18}$ Less numerous reports have described cases of progressive apraxia without dementia. ${ }^{19-22}$

Our case is concordant with progressive posterior occipitoparietal lobe degeneration pronounced on the right side. To the best of our knowledge, this characteristic of the focally degenerative syndrome was only reported by two authors ${ }^{21,23}$ without PET or SPECT imaging. De Renzi ${ }^{21}$ reported on 2 patients with a progressive impairment of visuoperceptive abilities (prosopagnosia, alexia, and constructional apraxia). Benson et al.,, ${ }^{23}$ in 5 patients, found deficits (with Balint's and Gerstmann's syndromes and dysphasia) that appeared to originate from bilateral parieto-occipital abnormalities. Visual topographic memory disturbances were the main clinical feature in our patient (Table 1). This progressive, isolated visual cognitive deficit was unusual in its severity and because of the absence of other symptoms resulting from widespread cerebral damage to other cortical areas until nearly 6 years after onset. These characteristics permit a conclusion on the relative specificity of this posterior syndrome contrasting with two other variants of progressive focal degenerative disease which include isolated deficits of language and apraxia (less frequently).

Little information is available on the neuropathology of this syndrome. However, from pathologic data on record in the literature, changes characteristic of variants of AD, 11.15 .20 Pick's disease, ${ }^{9.14}$ Creutzfeldi-Jacob disease (CJD), ${ }^{17.24}$ focal spongiform degeneration of superficial cortical layers, ${ }^{4.25}$ corticobasal ganglionic degeneration (with parietal and extrapyramidal signs), ${ }^{26}$ neuronal achromasia, ${ }^{27}$ as well as nonspecific histopathologic alterations ${ }^{15.18}$ occurred.

Data on the functional brain imaging obtained by PET or SPECT methods are quite numerous in the progressive aphasic and apraxic syndromes but are lacking in the two reports on the

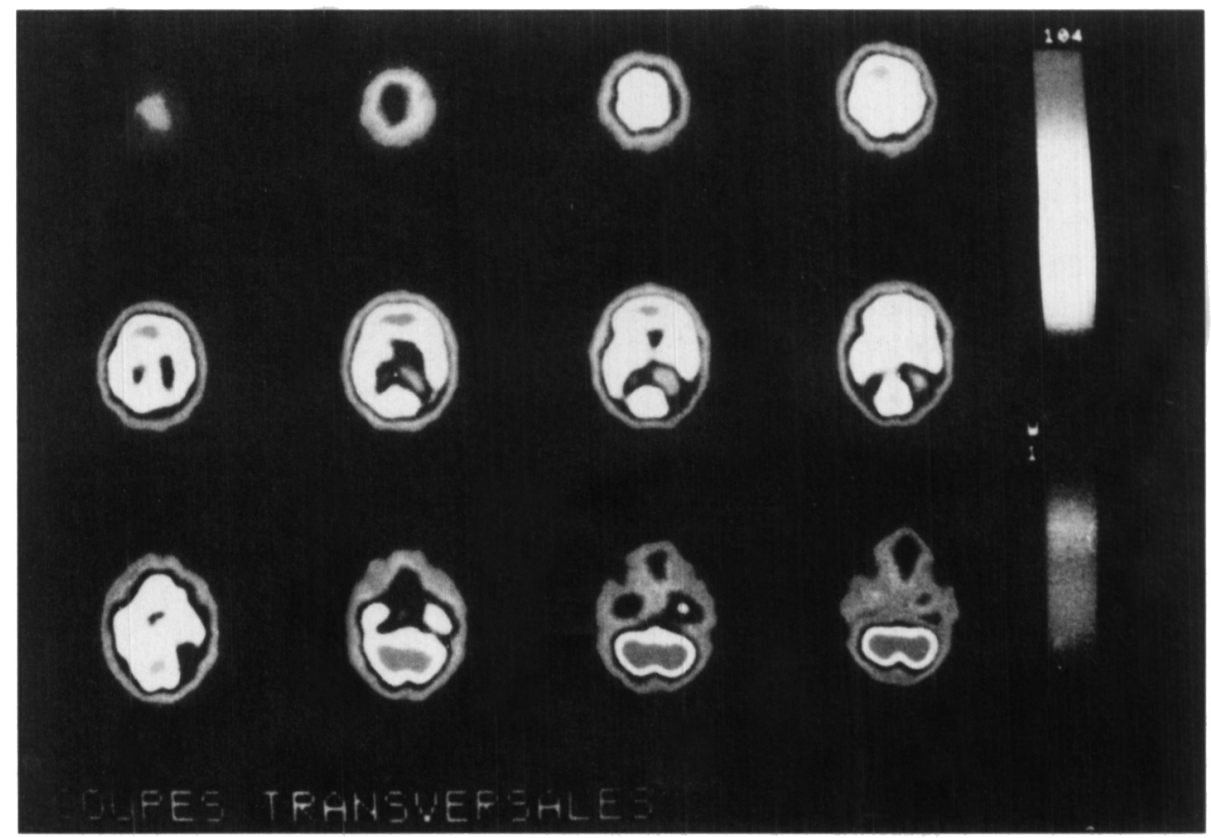

Figure 1 - SPECT study of ${ }^{99 m} T \mathrm{~T}-H M P A O$ uptake, showing marked hypoperfusion in the right parieto-occipital region with a milder effect in the homologous left associative region. 
Table 1. Clinical Characteristics of the Posterior Syndrome in our Case

Onset: Early visual dysfunction:

visual topographic memory:

visual constructive apraxia:

left visual extinction:

$++$

$+$

Course: Slowly progressive disturbances with:

visual topographic memory:

psychic paralysis of gaze:

simultagnosia:

optic ataxia:

visuospatial defects:

agnosia (visual and auditory):

apraxia (ideational and ideomotor):

Late stage: Amnestic syndrome :

confabulation:

loss of judgment:

confusion:
$+++$

$++$

$++$

$++$

$+$

$+$

$++$

$++$

$++$

$+++$ \pm : variable, + : mild, ++ : moderate, +++ : severe deficit

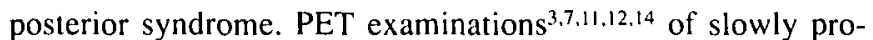
gressive aphasia have revealed left perisylvian and sometimes parietal hypometabolism. SPECT studies on patients with progressive language disorders ${ }^{13,25,28}$ have demonstrated abnormalities predominantly involving the fronto-temporal cortices in the left hemisphere. In cases of progressive apraxia, SPECT ${ }^{22}$ and $\mathrm{PET}^{19}$ have shown a decrease in the right and left posterior associative areas, marked predominantly on the right side and located in the superior ${ }^{22}$ or more inferior regions ${ }^{19}$ of the parietal lobe.

In dementia of the Alzheimer type, functional brain imaging by PET and SPECT has uncovered preferential abnormalities in the associative parietal and temporal cortices, later involving frontal areas; these deficits are correlated with the severity of the clinical findings and anatomo-pathologic lesions. ${ }^{29-32}$ Interhemispheric asymmetries may exist, especially when language (left temporal lobe) or visuo-spatial disorders (right parieto-occipital) predominate initially. ${ }^{32}$ In patients with frontal lobe dementia, probably of the non-Alzheimer type, there appears to be a tendency for the pathology to spread from the frontal to the temporal cortex, whereas in patients with progressive language disorders the obverse may be the case. ${ }^{25.30} \mathrm{It}$, therefore, seems plausible that the "Mesulam entity" will occur often on the basis of non-Alzheimer pathology, ${ }^{4,25}$ whereas the focally progressive posterior syndrome will probably often have Alzheimer pathology as in the case reported by Crystal et al. ${ }^{20}$

The clinical findings in our case, more consistent with a right parieto-occipital lesion, were relatively well correlated by morphologic and functional methods. CT scans revealed mild generalized atrophy more prominent in the right parieto-occipital lobe.

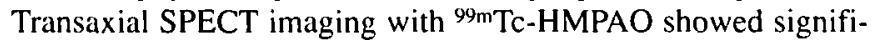
cant parieto-occipital hypoperfusion much more marked on the right side. These imagings are similar to previously reported patterns for probable AD with preponderant visuo-spatial dysfunction. Another possible cause in this patient, though much less common, could be Pick's disease, as proven by Cambier et al. ${ }^{33}$ in a postmortem case with a previously developed ( 9 years) left parietal syndrome. Lastly, the Heidenhain variant of CJD, can early and almost exclusively pathologically involve the occipital cortex, with dementia eventually becoming the pre- dominant clinical feature. ${ }^{34}$ These heterogenous possible etiologies showed up in neuropathological correlations ${ }^{35}$ of posterior cortical atrophy ${ }^{23}$ in 2 patients who came to autopsy. One case presented typical Alzheimer-type changes, and the other demonstrated severe gliosis with minimal demyelination and fine spongiform modifications in cortical lamina II. A third case developed clinical and EEG patterns of CJD.

Further clinical, functional (PET, SPECT), and pathologicallyverified cases are required to elucidate whether Mesulam's syndrome is an entity of progressive (over a period of years) focal degenerative disease without dementia until late in the course, or a progressive condition such as "asymmetric cortical degeneration" described recently. ${ }^{28}$ In this report, a focal degenerative syndrome predominated but other cognitive impairments occurred more frequently, especially in perceptuomotor and neuropsychiatric groups, and closely resembled dementia of either type.

\section{ACKNOWLEDGEMENT}

The authors thank Prof. M.I. Botez for reviewing, and Mrs. S. Pierrard for preparing this manuscript.

\section{REFERENCES}

1. Mesulam MM. Slowly progressive aphasia without generalized dementia. Ann Neurol 1982; 11: 592-598.

2. Mesulam MM. Primary progressive aphasia. Differentiation from Alzheimer's disease. Ann Neurol 1987; 22: 533-534.

3. Chawluk JB, Mesulam MM, Hurtig H, et al. Slowly progressive aphasia without generalized dementia: studies with positron emission tomography. Ann Neurol 1986; 19: 68-74.

4. Kirshner HS, Tauridag O, Thurman L, Whetsell WO Jr. Progressive aphasia without dementia: 2 cases with focal spongiform degeneration. Ann Neurol 1987; 22: 527-532.

5. Poeck K, Luzzatti C. Slowly progressive aphasia in three patients. The problem of accompanying neuropsychological deficit. Brain 1988; 111: 151-168.

6. Sapin LR, Anderson FH, Pulaski PD. Progressive aphasia without dementia: further documentation. Ann Neurol 1989; 25: 411. 413.

7. Croisile B, Laurent B, Michel D, et al. Différentes modalités cliniques des aphasies dégénératives. Rev Neurol 1991; 147: 192199.

8. Heath PD, Kennedy P, Kapur N. Slowly progressive aphasia without generalized dementia. Ann Neurol 1983; 13: 687-688.

9. Graff-Radford NR, Damasio AR, Hyman BT, et al. Progressive aphasia in a patient with Pick's disease: a neuropsychological, radiologic, and anatomic study. Neurology 1990; 40: 620-626.

10. Mendez MF, Zander BA. Dementia presenting with aphasia: clinical characteristics. J Neurol Neurosurg Psychiatry 1991; 54: 542 545.

11. Kempler D, Metter EJ, Riege WH, et al. Slowly progressive aphasia: three cases with language, memory, CT and PET data. J Neurol Neurosurg Psychiatry 1990; 53: 987-993.

12. Yamamoto $H$, Tanabe $H$, Kashiwagi A, et al. A case of slowly progressive aphasia without generalized dementia in a Japanese patient. Acta Neurol Scand 1990; 82: 101-103.

13. Delecluse F, Andersen AR, Waldemar G, et al. Cerebral blood flow in progressive aphasia without dementia. Case report, using 133Xenon inhalation, Technetium $99 \mathrm{~m}$ hexamethyl-propyleneamine oxime and single photon emission computerized tomography. Brain 1990; 113: 1395-1404

14. Salmon E, Sadzot B, Maquet P, Dive D, Franck G. Slowly progressive aphasia syndrome. A positron emission tomographic study. Acta Neurol Belg 1989; 89: 242-245.

15. Green J, Morris JC, Sandson J, Mckeel DW Jr, Miller JW Progressive aphasia: a precursor of global dementia? Neurology 1990; 40: 423-429. 
16. Scheltens PH, Hazenberg GJ, Lindeboom J, Valk J, Wolters ECH A case of progressive aphasia without dementia: temporal Pick's disease? J Neurol Neurosurg Psychiatry 1990; 53: 79-80.

17. Mandell AM, Alexander MP, Carpenter S. Creutzfeldt-Jacob disease presenting as isolated aphasia. Neurology 1989; 39: 55-58.

18. Mehler MF, Horoupian DS, Davies P, Dickson DW. Reduced somatostatin-like immunoreactivity in cerebral cortex in nonfamilial dysphasic dementia. Neurology $1987 ; 37$ : 1448-1453.

19. Léger JM, Levasseur M, Benoit N, et al. Apraxie d'apparition lentement progressive: étude par IRM et tomographie à positons dans 4 cas. Rev Neurol 1991; 147: 183-191.

20. Crystal HA, Horoupian DS, Katzman R, Jotkowitz S. Biopsyproved Alzheimer disease presenting as a right parietal lobe syndrome. Ann Neurol 1982; 12: 186-188.

21. De Renzi E. Slowly progressive visual agnosia or apraxia without dementia. Cortex 1986; 22: 171-180.

22. Dick JPR, Snowden J, Northen B, Goulding PJ, Neary D. Slowly progressive apraxia. Behav Neurol 1989; 2: 101-104.

23. Benson DF, Jeffrey DR, Snyder BD. Posterior cortical atrophy. Arch Neurol 1988; 45: 789-793.

24. Shuttleworth EC, Yates AJ, Paltan-Ortiz JD. Creutzfeldt-Jacob disease presenting as progressive aphasia. J Natl Med Assoc 1985; 77: 649-655.

25. Snowden JS, Neary D, Mann DMA, Goulding PJ, Testa HJ. Progressive language disorder due to lobar atrophy. Ann Neurol 1992; 31: 174-183.

26. Gibb WRG, Luthert PJ, Marsden CD. Corticobasal degeneration. Brain 1989; 112: 1171-1192.
27. Lippa CF, Cohen R, Smith TW, Drachman DA. Primary progressive aphasia with focal neuronal achromasia. Neurology 1991: 41: 882-886.

28. Caselli RJ, Jack CR Jr. Asymmetric cortical degeneration syndromes: a proposal clinical classification. Arch Neurol 1992; 49: 770-780.

29. Salmon E, Frackowiak RSJ. Neuro-imagerie fonctionnelle métabolique par émission de positons chez I'homme. Rev Neurol 1990; 8-9: 459-477.

30. Ohnishi T, Hoshi H, Nagamachi S, et al. Regional cerebral blood flow with ${ }^{123}$ I-IMP in patients with degenerative dementia. Am J Neuroradiol 1991; 12: 513-520.

31. Hurwitz TA, Ammann W. Chu D, et al. Single photon emission computed tomography using ${ }^{99} \mathrm{~m}$ Tc-HMPAO in the routine evaluation of Alzheimer's disease. Can J Neurol Sci 1991; 18: 59-62.

32. Chase TN, Foster NL, Fedio P, et al. Regional cortical dysfunction in Alzheimer's disease as determined by positron emission tomography. Ann Neurol 1984: 15 (Suppl): S170-S174.

33. Cambier J, Masson M, Dairou R, Henin D. Étude anatomo-clinique d'une forme pariétale de maladie de Pick. Rev Neurol 1981; 137: 33-38.

34. Van Rossem A. Spastic pseudosclerosis (Creutzfeldt-Jakob disease). In: Vinken PJ, Bruyn GW, eds. Handbook of Clinical Neurology. Amsterdam: North Holland Publishing Co. 1968 (v6, c28); 726-760.

35. Ross GW, Benson DF, Verity AM, Victoroff Jl. Posterior cortical atrophy: neuropathological correlations [abstract]. Neurology 1990; 40 (Suppl 1): 200. 